\title{
WATER TABLE LEVEL AS AN INDICATOR OF DROUGHT CONDITIONS
}

\section{By D. E. WILLIAMS ${ }^{1}$}

Received the degree of Bachelor of Science in Forestry from the University of Toronto in 1951. Following graduation joined the Federal Forestry Branch as a research officer in the Fire Protection Section. He was in charge of the Forest Fire Research Station in Manitoba's Whiteshell Forest Reserve in. 1951 and 1952 and is presently in charge of a similar station in Saskatchewan.

\section{ABSTRACT}

The effect of drought on heavy forest fuels is a basic factor in the Forestry Branch method of forest fire danger measurement. A method is described whereby, from an analysis of water table fluctuations, the drought factor table may be revised to include the effects of seasonal variations. Measurements were made in an undrained black spruce swamp. The effects of precipitation and temperature on water table level were determined, and expressed in a formula which could be used to prepare a drought index table.

Drought is one of the factors considered by the Forestry Branch of the Federal Department of Northern Affairs and National Resources in its system of forest fire danger rating. It is included chiefly because it provides an indication of the degree of inflammability of heavy fuels such as peat, and windfallen trees and branches. These fuels dry out at a slower rate than the lighter surface fuels, and their moisture content determines, largely, the degree of resistance of forest fires to control. The present method of including drought in fire danger rating calls for the use of a drought table from which the drought index is computed. This article seeks to describe recent studies of water table levels and to outline a method by which the Drought Table at present in use might be improved thereby. The improved Table would also provide a means for expressing seasonal variations in drought effect.

\section{BACKGROUND}

It is known that, in the absence of rain, heavy fuels do not have a constant rate of moisture loss, but that this rate varies seasonally and with changing weather conditions. In any area, the water supplied through precipitation is expended at varying rates by evaporation and, where living plants are in contact with the fuels, also by transpiration.

Thornthwaite (6) has stated that: "We cannot tell whether a climate is moist or dry by knowing the precipitation alone. We must know whether precipitation is greater or less than the water needed for evaporation and transpiration." The problem, then, is to find a measure of this water use, under different seasonal and weather conditions, and to relate it to the quantity of water supplied. An undrained swamp is, in effect, an instrument from which, by noting the water table fluctuations, some estimate of this water use can be ${ }^{1}$ Fonestry Branch, Department of Northern Affairs and National Resources, Ottawa.

Manuscript received for publication September 15, 1954. 
obtained. The data for the present study were obtained from pits located in such a swamp.

Moreover, the water level data collected in these investigations may well be of some value in the field of evapo-transpiration study where they may help fulfill the need for empirical data to supplement run-off measurements used as a check on existing formulae.

\section{Method of Study}

The present study was carried out in conjunction with other forest fire research projects at the Whiteshell Forest Reserve near Rennie, Manitoba. Three water-table level pits, referred to as "seepage pits", were dug in an extensive black spruce swamp having a ground cover of Sphagnum and Ledum. The pits were made eighteen inches square and from three to four and onehalf feet deep.

A fourth pit was dug in a small alder swamp some distance from, and at a higher elevation than, those within the spruce swamp. The purpose of this fourth pit was to determine whether the changes in water level in small, noncontiguous swamps were proportional to those occurring in extensive muskeg areas. A comparison of the water level readings obtained, indicated that the variations in water level in all four pits were in sufficiently close agreement to enable the data obtained from any one to be considered as representative of all.

Daily water level readings were made, to the nearest tenth of an inch, with graduated rods permanently driven into the bottom of each pit.

A recording water level gauge to supply a continuous tracing was designed and set up over one of the pits. This supplemented the daily readings from the rods and provided a means of studying the diurnal behavior of the water table as well as the nature of the rise in water level resulting from various quantities of precipitation.

Observations at Whiteshell extended over the fire seasons of 1949, 1950, and 1951. Additional water level data have been obtained at other Forest Fire Research Stations, but there are not enough data from these sources yet to warrant their inclusion.

The weather data used in all correlations were obtained from instruments located in the open at a headquarters site situated some one hundred yards from the seepage pits. For the purpose of making certain fundamental studies it would be necessary to locate the weather instruments as close as possible to the seepage pits. However, to make practical use of the findings, it would then be necessary to correlate the weather data recorded at the pits with those recorded at a nearby fire weather station. For the purpose of this investigation the water level variations were correlated directly with the fire weather station data; in this way, the "on-the-site" weather observations were by-passed and the required final relationship was obtained.

\section{ANALYSIS}

Virtually all the drop in water level, during drying weather, occurred during daylight hours as shown by the recording water level gauge whose tracing on the graph remained horizontal during the night. This simplified the study 
because it may be assumed that the rate of recharge (other than precipitation) is equal to the rate of discharge, or that both are nil. Thus, any inflow or outflow of the water in the observed swamp need not be considered in a study of this nature so long as the night-time tracing remains horizontal.

As it was not practicable under existing circumstances to attempt to ascertain a zero, or starting, water level, and since only the differences in successive daily observations were required, the day-to-day variations in water level were used in the analysis.

Since the change in water table level from the preceding day may have been positive or negative, it was necessary to treat separately the factors causing a rise and those causing a fall in the water level.

\section{(a) Precipitation Effect}

Observation showed that precipitation is the only factor which causes a rise in water table level in the area under study. The relationship between the amount of precipitation in inches and the resulting rise of the water table was found to be well represented by a straight line of the equation $Y=-0.286+3.5 x$, where $X$ represents the resulting rise in water level in inches and $x$ the amount of precipitation (also in inches). When an inch of water is added to the soil, the water table will rise one inch times a converting factor ( 3.5 in the above equation) to allow for that portion of the space occupied by the soil. This factor, as described by Kittredge (2) is called the "specific yield" and varies with the type of soil concerned. By applying a rainfall of 0.5 inches in the foregoing equation, a resulting rise of 1.46 inches in water level is indicated. Then, by applying these sample values to the formula for specific yield, $Y=$ $100 \mathrm{dw}^{*}$, described by Kittredge, a value of 34.2 per cent is obtained for the

Ds

specific yield of the peat soil in the area under consideration. The fact that this value agrees favorably with those quoted by Kittredge verifies, to some extent, the empirical rainfall equation arrived at in this study and given above.

\section{(b) Evapo-transpiration Effect}

Since the water table of the area in question is not affected by drainage, the water level will fall, during dry weather, at a rate dependent upon the amount of water expended in evaporation and transpiration. The effectiveness of these functions is dependent upon such factors as air temperature, humidity, solar radiation, and wind velocity, and there are indications that the effects of these factors may be interrelated.

In order to prevent the study from becoming highly involved, and to prepare the data for ready application in field usage, it was considered desirable to determine which single weather element had the greatest correlation with the rate of fall of the water table. Correlative analyses were made of daily water level variations, during dry weather, with relative humidity, hours of bright

\footnotetext{
$* d w=$ depth of water added

Ds $=$ rise in water level
} 
sunlight, air temperature, wind velocity, and dew point depression respectively. It was found that by far the best correlation was obtained by using air temperature against fall in water level. This conclusion is well substantiated in current literature on evaporation and transpiration studies. Evaporation estimates have been based, as a rule, on two lines of reasoning: "turbulent transport," and "energy balance". Evaporation and transpiration formulae evolved by Thornthwaite and Cummings (1) for North America, and by Penman (5) for the British Isles, are based on both approaches and all use air temperature as a very prominent factor. Transpiration and growth, as well as evaporation, increase with an increase in air temperature under the normal growing temperature range. Thornthwaite states: "Although solar radiation is the basic factor, there seems to be a closer parallelism between air temperature and transpiration." Meyer (4) points out that: "The effect of a rise in (air) temperature ... is principally an increase in the diffusion gradient (vapor pressure gradient) of water vapor through the stomates, and hence an increase in the rate of transpiration". In a discussion of diurnal fluctuations in ground water, Troxell (7) observes that "maximum transpiration will occur at a point showing the maximum rate of drop in the ground-water table. This point of maximum use occurs at or near the time of maximum temperature".

A graphic correlation between noon air temperature and the day's decrease in water table level was plotted using the data for all days on which there was no precipitation. A standard error of estimate of \pm 0.15 inches was obtained with the resulting curve. An error of this order would be equivalent to a rainfall of 0.04 inches.

\section{Practical Application}

Part of the object of this study, as previously stated, is to outline a method whereby the present Drought Table could be revised to include seasonal variations in drought effect. Two curves have been established: one for precipitation, which results in a rise of water level, and one for temperature, the drying effect of which causes a fall in water level. A value for the specific yield of the soil involved has also been established. A tentative drought table has been drawn up from values based on the precipitation and temperature curves. The specific yield value for the soil was used to determine the quantity of precipitation expended per drying day, thus:

Precipitation expended $=$ fall in water level $\times$ specific yield of soil

100

or, by making use of the symbols given by Kittredge, the formula may be represented thus:

$$
d w=\frac{\text { Ds } x y}{100}
$$

As a simplifying step in drawing up a revised table, normal temperatures were substituted for daily observed temperatures with the result that precipitation is the only weather factor that need be considered daily as is so with the present Drought Table. The use of such temperature figures insures the taking into account of the effect of normal seasonal variations. 
A comparison of the normal monthly mean noon temperatures for Pinawa" and the Whiteshell monthly mean noon temperatures, over the four years of the latter station's existence, showed an agreement to within $4^{\circ} \mathrm{F}$. for 87.5 per cent of the time, and to within $7^{\circ} \mathrm{F}$. for 94 per cent of the time. These results would indicate that normal temperature values could well be used in the development of a drought table, the accuracy of which would compare favorably with that of a similar table based on the use of actual temperatures.

In the graph below, "Normal Water Table Level", the values for water expended were obtained by applying Pinawa normal temperatures and were

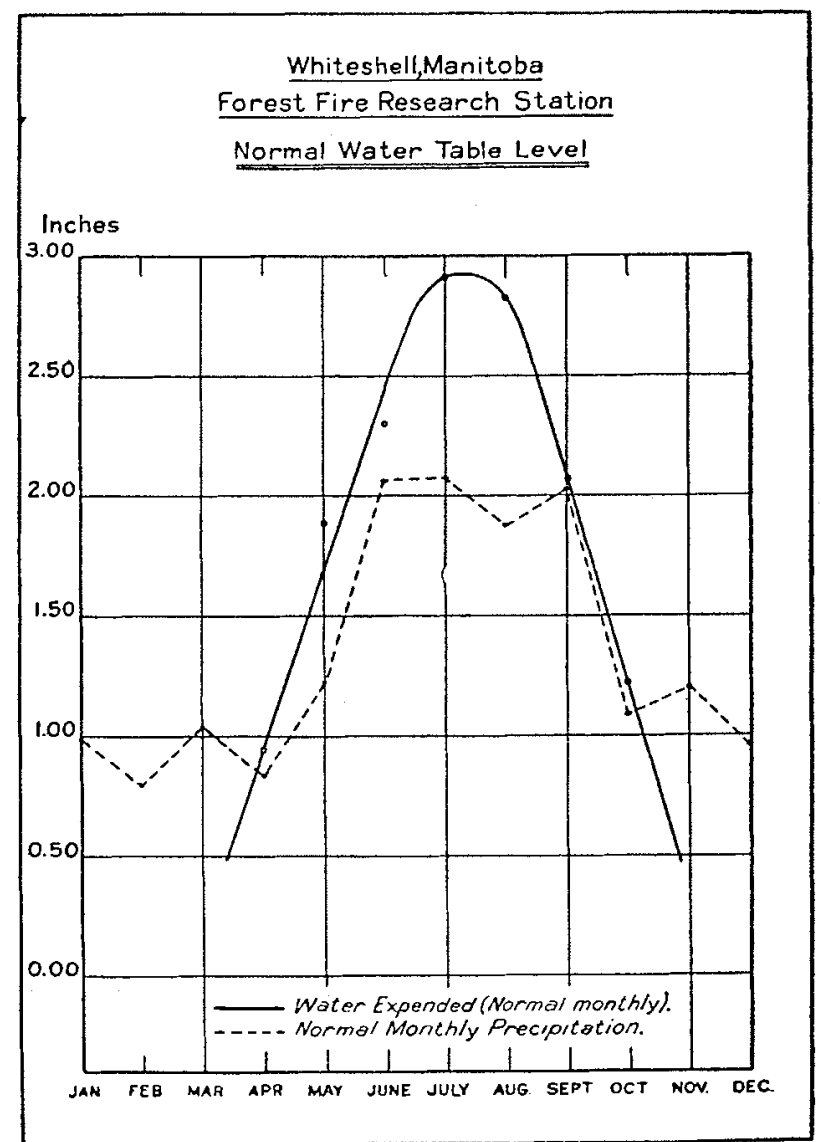

"The normal values used were obtained from twenty-two years" data collected at Pinawa, Manitoba (3), the Meterological Service weather station nearest the Whiteshell Fire Research Station. Normal noon values were obtained from normal maximum and minimum values by ploting sine curves between the latter two figures. 
plotted, with normal precipitation, over the year, by months. From it, the following considerations are apparent:

(a) The probability of drought conditions occurring is consistently higher during certain portions of the year. Normally, the precipitation for the period May to September, inclusive, is much greater than that for the remainder of the year. However, during these warm months, the water obtained through normal precipitation is exceeded by the water expended by evaporation and transpiration. As a result, this period may be regarded as being "potentially dry", since the rate of moisture loss from peaty and heavy fuels is more rapid, and a lack of precipitation will have a much greater effect than at any other time throughout the year. As a result, serious drought conditions are more likely to occur during this period.

(b) The normal precipitation during the months of April and October is not great -0.84 and 1.09 inches respectively at Pinawa-but is sufficient to fill the water need. If, however, there be extremely little or no precipitation during these months, and no lasting snow on the ground, drought conditions could develop. The rate of moisture loss in April and October, however, is not nearly as rapid as during the summer months and any drought condition which developed then. would be less serious than a similar drought which occurred in the intervening period.

(c) During the winter period, November to March, with low temperatures and normal snow conditions, transpiration and evaporation are almost nonexistent, and even the light precipitation received during this period exceeds the water need. Part of this excess is stored in the soil and peaty fuels as a surplus which is effective, to some extent, in reducing the chances of drought occurrence during the early part of the following fire season.

\section{REFERENCES}

1. CUMMINGS, N. W. The evaporation-energy equations and their practical application. In Trans. Am. Geophys. Union 21: 512-522, 1940.

2. KITTREDGE, JOSEPH. Forest influences. McGraw-Hill, Toronto, 1948.

3. Meteorological Service of Canada. Climatic summaries for selected meteorological stations in the Dominion of Canada. Vol. 1. Canada, Dept. of Transport. Toronto, n.d.

4. MEYER, BERNARD S., and ANDERSON, DONALD B. Plant physiology. D. Van Nostrand, New York, N.Y. 1940.

5. PENMAN, R. L. Evaporation over the British Isles. Quart. J. Roy. Meteor. Soc. 76 (No. 330): 372-383, Oct. 1950.

6. THORNTHWAITE, C. W. An approach toward a rational classification of climate. Geog. Rev. XXXVIII (No. 1): 55-94, Jan., 1948.

7. TROXELL, HAROLD C. The diurnal fluctuations in the ground water and flow of the Santa Ana river and its meaning. In Trans. Am. Geophys. Union Pt. 2. 1936. 